\title{
ATIVIDADE REPRODUTIVA DE BAIRDIELLA RONCHUS (CUVIER) (PISCES, SCIAENIDAE) NA BAÍA DE GUARATUBA, PARANÁ, BRASIL ${ }^{1}$
}

\author{
Paulo de T. da Cunha Chaves ${ }^{2}$
}

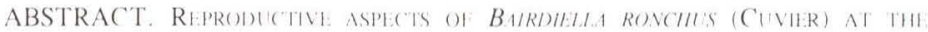
GuARAIIBA BAy. PARANA. Bra/l Bairdiella ronchus is one of the most common species of demersal ichthyofauna in Guaratuha Bay, south Brazil. However. this study reveals that is does not inhahits permanently the mangroove area. Individuals with more than $94 \mathrm{~mm}$ total lenght leave mangroove area in late summer and early autumn and returning in the spring, when they start ovarian vetellogenesis. Durmg late spring and early summer, the oocytes are hodrated, and empty follicles can be found in the ovaries. indieating that this is the repreductive tame for this species. A. other Sciaendae. B. ronchus is a multuple spawner species.

KEY WORDS. Pisces. Sciaenidae. Bairdiella ronchus
\end{abstract}

A Baía de Guaratuba situa-se no litoral do Estado do Paraná (2552'S, $48^{\circ} 39^{\circ} \mathrm{W}$ ), ligando-se ao mar por uma abertura de aproximadamente $500 \mathrm{~m}$, e estendendo-se continente adentro por cerca de $15 \mathrm{Km}$. Sua margem norte, a mais provida de aportes fluviais, apresenta-se como um manguezal, com poços cuja profundidade atinge pelo menos sete metros, e com valores de temperatura da água oscilando entre 16 e $30^{\circ} \mathrm{C}$. e de salinidade podendo ultrapassar 30ppmil (observação pessoal). A ictiofauna da regiāo é aquela típica de ambientes marinhos e estuarinos, sendo particularmente comuns as espécies de Ariidae. Haemulidae. Gerreidae, Sciaenidae, Tetraodontiformes e Pleuronectiformes. O bagre Genidens genidens (Valenciennes, 1839), por exemplo, desova na região (CHAVES 1994).

Dentre as espécies de fundo mais abundantes na Baía, uma é Bairdiella ronchus (Cuvier, 1830), localmente conhecida como "oveva" (também como "canguá" ou "roncador" (MENEZES \& FiguEIREDO 1980). Bairdiella ronchus, ao contrário de vários outros Sciaenidae, não é apreciada comercialmente, o que talvez explique o pequeno conhecimento biológico existente a seu respeito. Sabe-se que se distribui do Caribe a Santa Catarina, alimentando-se principalmente de crustáceos e peixes (MENEzES \& FigUEIREDO 1980). Aspectos relacionados a sua biologia reprodutiva, porém, são ainda inexistentes. Assim, este trabalho investiga a ocorrência de atividade reprodutiva de $B$. ronchus na área de manguezal da Baía de Guaratuba, tendo como objetivo disponibilizar mais informaçōes sobre a

1) Contribuç̨ão número 909 do Departanento de Zoologla, Universidade Federal do Paraná. Realizado com recursos do CNPq e I.UNPAR/UFPR

2) Departamento de Zoologia. Universidade Federal do Paraná. Caixa Postal 19020.81531-990) Curitiba, Paraná, Brasil. 
espécie, bem como, num trabalho multiespecífico e de longo prazo, contribuir para que se melhor avalie a importância daquele ambiente para o ciclo de vida dos peixes da região.

\section{MATERIAL E MÉTODOS}

Exemplares de Bairdiella ronchus foram coletados na Baía de Guaratuba mensalmente, entre setembro de 1993 e junho de 1995, exceto em maio/1995. Utilizou-se rede de arrasto de fundo com portas, operada por pescador profissional, com quatro a seis lances por mês, cada lance tendo duração aproximada de seis minutos, todos em uma mesma manhã e em diferentes pontos do manguezal (Fig. 1). Em alguns meses, tarrafa e rede de cerco também foram empregadas, porém não demonstraram eficiência para catura da espécie.

Com exceção da coleta de janeiro/95, quando sub-amostragem teve que ser realizada e uma parte dos exemplares rejeitada a bordo, nos demais todos os exemplares capturados foram transportados em gelo para laboratório, garantindose que fossem trabalhados ainda frescos. O número total de exemplares analisados foi 420 , e deles se quantificou o comprimento total e o peso total. As gônadas de 341 destes exemplares foram extraídas, pesadas sempre que possível, e avaliadas macroscopicamente quanto a sexo e estágio de maturação. De cada uma de vinte e duas fêmeas, um dos ovários foi fixado em solução de formalina a $10 \%$, para processamento histológico de rotina, com inclusão em parafina e coloração HE. O grau de maturação dos folículos ovarianos foi avaliado por comparação com as informaçōes histológicas já disponiveis para outras espécies de Sciaenidae (CHA VES 1985, 1989a; ISAAC-NAHUM \& VAZZOLER 1987; HAIMOVICI \& COUSIN 1989; BARBIERI et al. 1994).

Para avaliação da atividade reprodutiva, utilizaram-se como indicadores: volume, coloração e vascularização gonadais, a granulometria aparente (apenas para ovários), a tendência à eliminação de esperma sob pressão manual (nos machos), e ainda, histologicamente, o grau de vitelogênese dos ovócitos e a ocorrência de folículos hidratados, vazios (=pós-ovulatórios), e atrésicos. Foi, ainda, considerada a variação mensal dos valores da Relação Gonadossomática, calculada segundo VAzzoler (1981): $R G S=\begin{gathered}\text { Peso das gônodas } \\ \text { Peso do corpo }\end{gathered}$ Peso do corpo = peso total - peso das gônadas.

Para apresentação dos valores da Relação Gonadossomática, as médias foram tratadas separadamente por sexo e divididas em três classes: valores menores que 1,0 , entre 1,0 e 4,0 , e maiores que 4,0 .

\section{RESULTADOS}

A figura 2 apresenta a distribuição mensal do número de indivíduos coletados e sua amplitude de comprimento, indicando que $B$. ronchus foi mais abundante nos meses de primavera e verão que nos de outono e inverno. Foi também naquelas duas estações que se registraram os indivíduos de maior porte. O maior de todos, um macho de $198 \mathrm{~mm}$, foi coletado em novembro/93. 


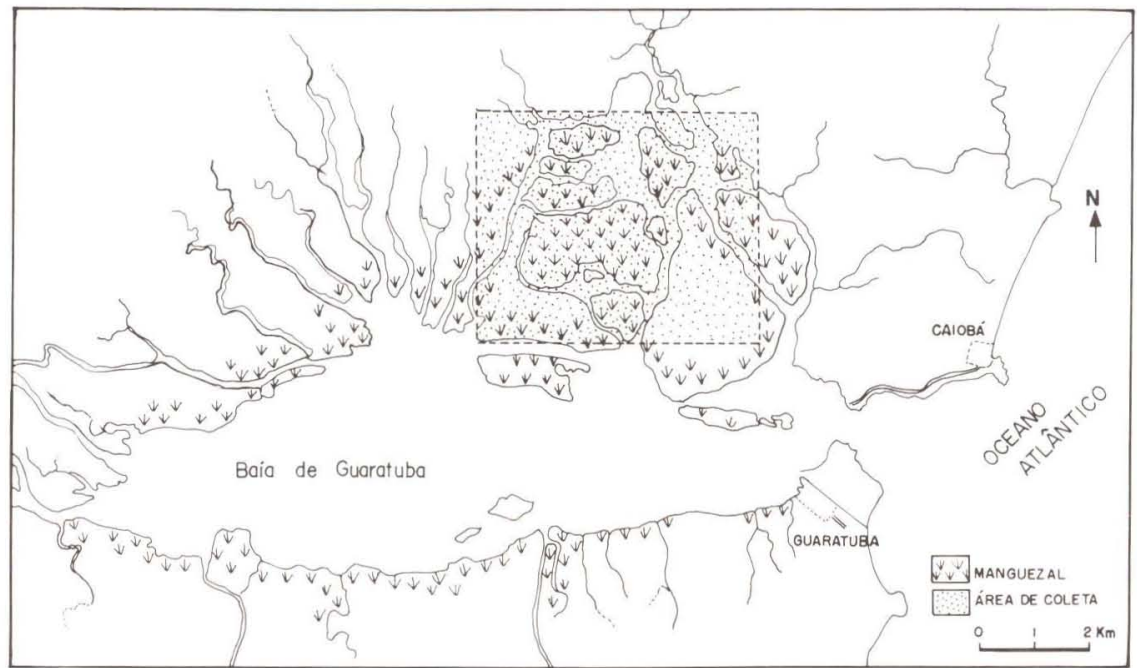

Fig. 1. Localização da área de estudo (retângulo pontilhado) dentro da Baía de Guaratuba, litoral do Paraná $\left(25^{\circ} 52^{\prime} \mathrm{S}, 48^{\circ} 39^{\prime} \mathrm{W}\right)$.

A análise histológica dos ovários permitiu acompanhar o desenvolvimento dos ovócitos a partir de uma etapa pré-vitelogênica, apresentando nucléolos múltiplos e citoplasma basófilo (Fig. 3a); a seguir, uma fase de vitelogênese inicial, com gotículas cromófobas depositadas a partir da região perinuclear, mas eventualmente se dispersando por todo o citoplasma; em ovócitos maiores, grânulos vitelínicos acidófilos também foram reconhecidos (Fig. 3a); ovócitos maduros, mais volumosos que os anteriores, caracterizaram-se por já não mais apresentarem basofilia citoplasmática, mas sim grânulos vitelínicos acidófilos e gotículas cromófobas homogeneamente misturados (Fig. 3b); por fim, registrou-se uma fase de hidratação pré-ovulatória, em que o ovócito é muito grande, o citoplasma parcial ou totalmente hialinizado, e o núcleo localizado em posição excêntrica (Fig. 3c). Em alguns ovários, foram registrados ainda folículos vazios (células foliculares não circundando ovócito - Fig. 3d) e folículos atrésicos, com degeneração parcial dos envoltórios do ovócito e/ou de seus grânulos de vitelo (Fig. 3e).

Conjugando-se as informações macroscópicas com as da análise histológica, o desenvolvimento dos ovários foi classificado em seis estágios:

Imaturo (A). Macroscopicamente translúcido e claro, sem ovócitos distinguíveis a olho nu. Histologicamente, apenas ovócitos pré-vitelogênicos (Fig. 3f).

Em maturação (B). Coloração rósea, eventualmente com ovócitos distinguíveis a olho nu. Histologicamente, além de ovócitos pré-vitelogênicos, presença também de ovócitos em vitelogênese (Fig. 3g).

Maduro (C). Ovário com maior volume, amarelado, repleto de ovócitos de diferentes tamanhos, todos opacos. Macroscopicamente, presença de lotes de ovócitos pré-vitelogênicos, vitelogênicos e maduros (Fig. 3h). 


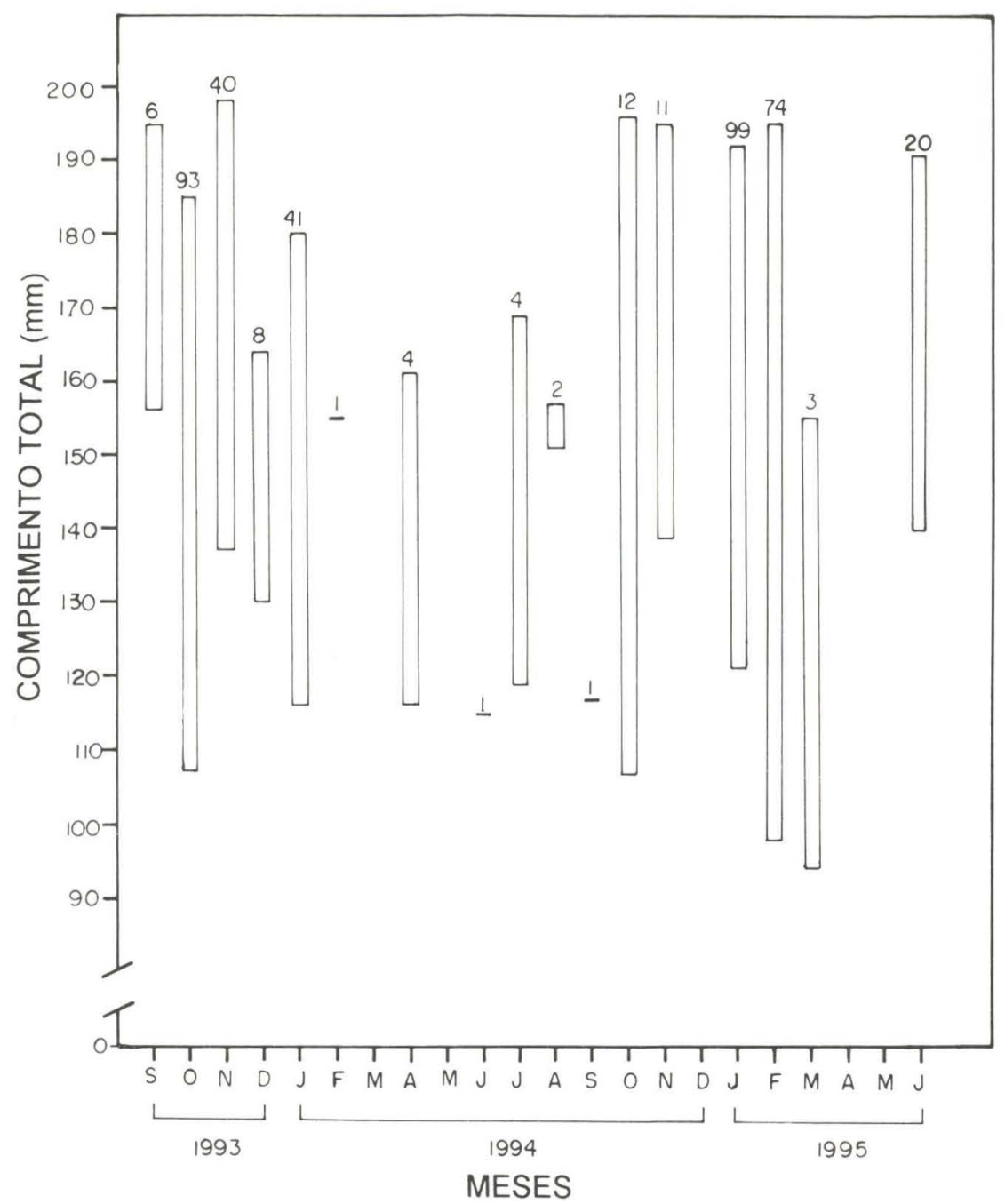

Fig. 2. Distribuição mensal da amplitude de comprimento de $B$. ronchus nas coletas efetuadas. Os valores sobre as colunas indicam o tamanho da amostra.

Em hidratação (Ch). Difere macroscopicamente do anterior por apresentar um lote de ovócitos alaranjados translúcidos, maiores que os demais. Histologicamente, além das fases anteriores, presença de ovócitos em hidratação pré-ovulatória.

Maduro pós-desova (C2). Ovário levemente avermelhado, contendo áreas de flacidez em seu interior. Histologicamente, constata-se a ocorrência de um lote de folículos vazios, simultaneamente a lotes de ovócitos maduros, em maturação e pré-vitelogênicos (Fig. 3i). 

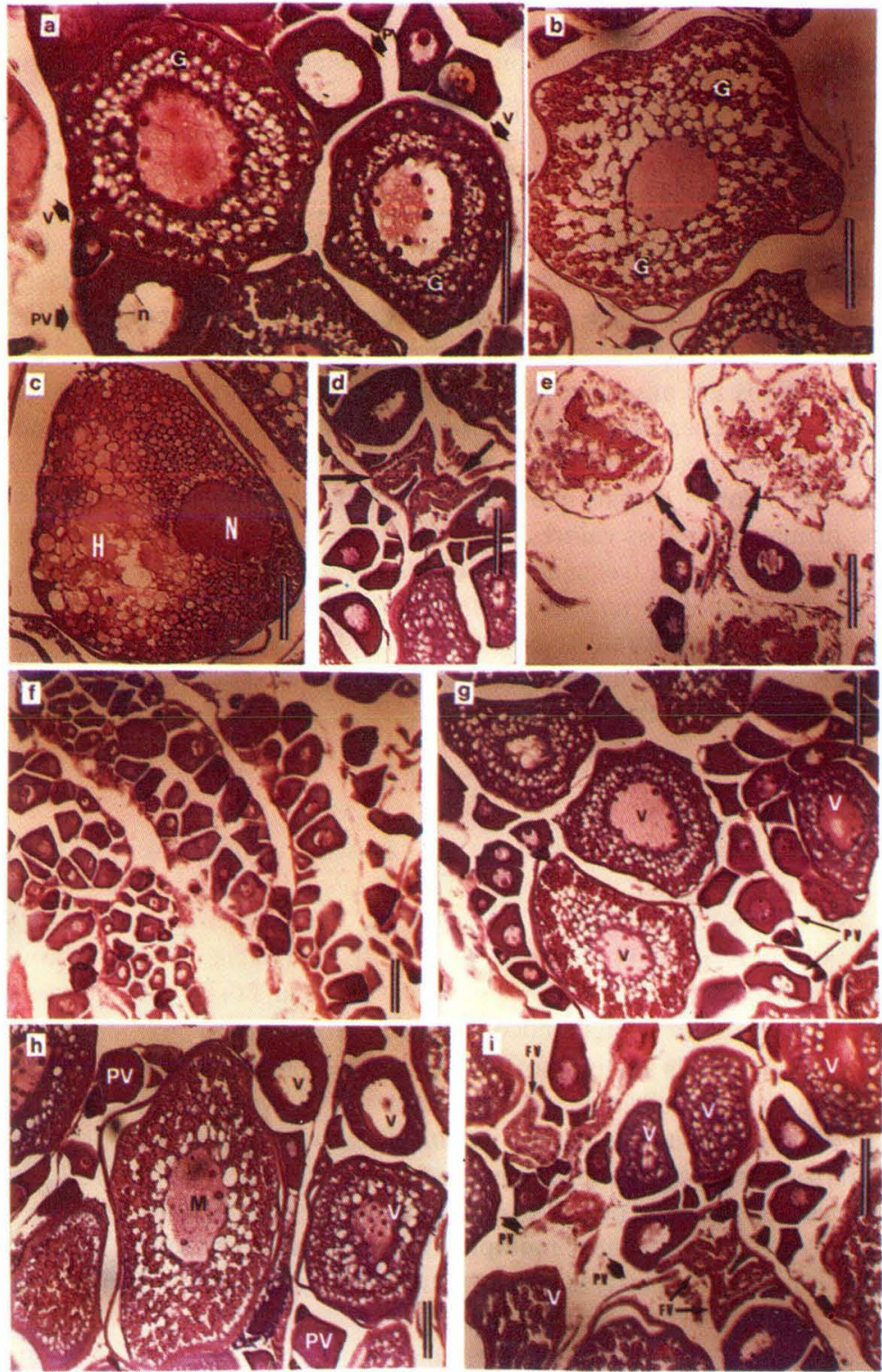

Fig. 3. Aspectos do desenvolvimento ovariano em B. ronchus. (3a) Ovócitos basófilos, pré-vitelogênicos (PV), e em vitelogênese (V), estes contendo grânulos de vitelo (G). São indicados os nucléolos ( $\mathrm{n}$ ); (3b) Ovócito maduro (grânulos de vitelo - G); (3c) ovócito em hidratação pré-ovulatória, com núcleo em localização excêntrica (N) e citoplasma parcialmente hialinizado (H); (3d) folículos vazios (setas); (3e) folículos atrésicos (setas). Na seqüência, diferentes estágios de maturação: (3f) ovário imaturo, (3g) em maturação, (3.h) maduro e maduro pós-desova (3.i), podendo apresentar ovócitos pré-vitelogênicos (PV), ovócitos em vitelogênese (V), ovócitos maduros (M), e/ou folículos vazios (FV). Barras = $0,1 \mathrm{~mm}$. 
Em recuperação (R). Ovário com menor volume que no estágio anterior, apresentando pontos hemorrágicos e poucos ovócitos distinguíveis macroscopicamente. Nas secções histológicas são encontrados ovócitos pré-vitelogênicos, folículos atrésicos e tecido conjuntivo hemorrágico. A presença de folículos vitelogênicos e maduros é apenas ocasional, não constituindo lotes.

Consideraram-se como fêmeas "em atividade reprodutiva" aquelas cujos ovários se encontravam em estágio $\mathrm{C}, \mathrm{Ch}, \mathrm{C} 2$ ou $\mathrm{R}$. No caso dos machos, foram considerados nesta condição os indivíduos cujos testículos macroscopicamente tinham apresentação leitosa, eliminando esperma sob pressão manual.

Indivíduos em atividade reprodutiva foram mais frequentes na primavera que em outras estações. Reunindo-se os dois anos de amostragem e tratando-se os sexos conjuntamente, estavam em reprodução mais que $80 \%$ dos indivíduos coletados em outubro, e mais que $90 \%$ dos coletados em novembro (Fig. 4). Foi ainda na primavera que os valores de RGS alcançaram suas maiores médias (Fig. 4). Em ambos os anos, a frequência média de indivíduos em atividade reprodutiva decaiu a menos que $20 \%$ no mês de janeiro; ao meio do verão, em fevereiro dos dois anos, já não mais foram registrados indivíduos nesta condição. Os menores comprimentos de machos e fêmeas que estavam em atividade reprodutiva foram, respectivamente, $107 \mathrm{~mm}$ e $138 \mathrm{~mm}$.

\section{DISCUSSÃO}

A apresentação histológica do processo de vitelogênese em Bairdiella ronchus assemelha-se, num plano geral, àquela já conhecida em outros Sciaenidae (ISAAC-NAHuM \& VAZZOLER 1987; Chaves 1989a,b; HAIMOVICI \& Cousin 1989; BARbieri et al. 1994). Porém, ao final da vitelogênese, os ovócitos de $B$. ronchus sofrem uma pronunciada hidratação pré-ovulatória, fato que os difere daqueles de Sciaenidae de água doce (CHAves 1985, 1989b).

Os resultados da análise morfológica sobre a maturação gonadal, bem como os da análise da distribuição de valores da Relação Gonadossomática, indicam que a região estudada é sítio de desova de Bairdiella ronchus. O período de desova concentra-se na primavera, mas, com menor intensidade, pode-se estender até o início do verão. A julgar pelo tipo de desenvolvimento dos ovócitos - em vários lotes, a desova provavelmente é múltipla, o caso comum reconhecido para a família (ChAves 1985; ISAAC-NAHUM \& VAZZOLER 1987; GoldberG 1981; HaIMOVICI \& COUSIN 1989; BARBIERI et al. 1994).

O comprimento do maior exemplar capturado no manguezal da Baía de Guaratuba - $198 \mathrm{~mm}$, foi bastante inferior ao valor máximo registrado para o sul/sudeste por MENEzES \& FigueIREDO (1980) - 35cm. Assim, pode-se estimar que nesta área os indivíduos de $B$. ronchus alcancem um porte apenas médio, embora completando plenamente a maturidade gonadal.

Apesar de no outono e inverno os exemplares capturados terem sido, de um modo geral, menores que aqueles da primavera e do verão, ainda assim muitos deles eram frequentemente maiores que $107 \mathrm{~mm}$ (machos) ou $138 \mathrm{~mm}$ (fêmeas), comprimentos em que os indivíduos já podem ser considerados adultos. Tal fato 
demonstra que a ausência de indivíduos em atividade reprodutiva naquelas estações não foi provocada pelo tamanho dos exemplares analisados, mas sim porque, de fato, durante o outono e o inverno a espécie não se reproduz nesta área.

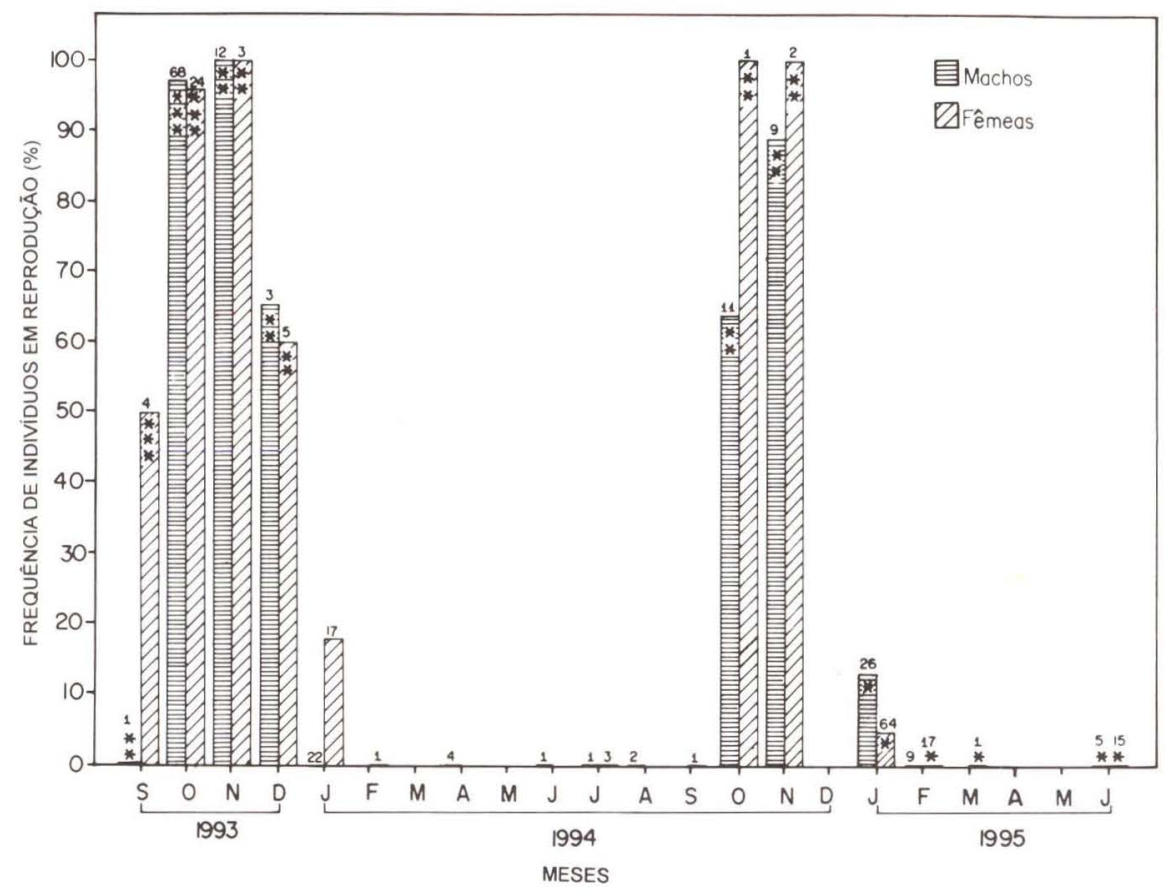

Fig. 4. Variação mensal da frequência de ocorrência de indivíduos em atividade reprodutiva, segundo o sexo. Acima de cada coluna indica-se o número de exemplares analisados. $\mathrm{Na}$ porção superior interna de cada coluna, representa-se o valor médio de RGS no mês (quando mensurado). $\left({ }^{*}\right)$ Inferior a 1,$0 ;\left(^{* *}\right)$ entre 1,0 e 4,$0 ;\left({ }^{* *}\right)$ superior a 4,0 .

A maior abundância de captura nos meses de primavera e verão que naqueles de outono e inverno, considerando-se que o esforço amostral foi aproximadamente uniforme em todas as coletas, indica a possibilidade de os indivíduos efetuarem deslocamentos sazonais para dentro e para fora da área de manguezal. Tal movimentação envolveria pelo menos os indivíduos situados na faixa de tamanho pesquisada (maiores que $94 \mathrm{~mm}$ ), que na época de primavera ocupariam o manguezal para aí finalizar a maturação gonadal e o processo de reprodução. Possivelmente, durante o outono e o inverno a maior parcela da população de $B$. ronchus se disperse por outras regiões, que não a do manguezal.

AGRADECIMENTOS. Ao acadêmico Dalton T.R. dos Santos, pela arte final das ilustrações a nanquim, ao Prof. W. Boeger, pela correção do abstract (ambos da Universidade Federal do Paraná), e ainda a dois Revisores anônimos. 


\section{REFERÊNCIAS BIBLIOGRÁFICAS}

Barbieri, L.R.; M.E. Chittenden JR. \& S.K. Lowerre-Barbieri. 1994. Maturity, spawning, and ovarian cycle of Atlantic croacker, Micropogonias undulatus, in the Chesapeake Bay and adjacent coastal waters. Fishery Bulletin 92 (4): $671-685$.

ChAves, P. DE T. DA C. 1985. O desenvolvimento ovocitário em representantes de dez famílias de teleósteos amazônicos: aspectos estruturais e considerações ecológicas. Dissertação de Mestrado, não publicada, Instituto Nacional de Pesquisas da Amazônia, Universidade do Amazonas, Manaus, 83p. . 1989a. Desenvolvimento dos ovócitos em Harengula clupeola, Urophycis brasiliensis, Eucinostomus argenteus, Isopisthus parvipinnis e Menticirrhus americanus (Teleostei). Bolm Inst. oceanogr., São Paulo, 37 (2): 81-93.

1989b. Hidratação pré-ovulatória em peixes: um caráter de origem marinha? Revta bras. Zool. 6 (3): 463-472.

. 1994. A incubação de ovos e larvas em Genidens genidens (Valenciennes) (Siluriformes, Ariidae) da Baía de Guaratuba, Paraná, Brasil. Revta bras. Zool. 11 (4): 641-648.

GoldBerg, S.R. 1981. Seasonal spawning cycle of the black croaker, Cheilotrema saturnum (Sciaenidae). Fishery Bulletin 79 (3): 561-562.

Haimovici, M. \& J.C.B. Cousin. 1989. Reproductive biology of the castanha Umbrina canosai (Pisces, Sciaenidae) in Southern Brazil. Rev. Brasil. Biol. 49 (2): 523-537.

ISAAC-NAHUM, V.J. \& A.E.A. DE M. VAZZOLER. 1987. Biologia reprodutiva de Micropogonias furnieri (Desmarest, 1823) (Teleostei, Sciaenidae). 2. Relação gonadossomática, comprimento e peso dos ovários como indicadores do período de desova. Bolm inst. oceanogr., São Paulo, 35 (2): 123-134.

Menezes, N.A. \& J.L. Figueiredo. 1980. Manual de Peixes Marinhos do Sudeste do Brasil. IV. Teleostei. Museu de Zoologia, Universidade de São Paulo. São Paulo, 96p.

VAzzoler, A.E.A. DE M. 1981. Manual de Métodos para Estudos Biológicos de Populações de Peixes. Reprodução e Crescimento. Brasília, CNPq, 108p. 